\title{
Ultrasound-guided interscalene brachial plexus block in a pediatric patient with acute hepatitis
}

\section{-A case report-}

\author{
Joon-Ho Lee, Young-Rok Kim, Ho-Kyung Yu, Sung-Hwan Cho, Sang-Hyun Kim, and Won Seok Chae
}

Department of Anesthesiology and Pain Medicine, Soonchunhyang University, Bucheon Hospital, Bucheon, Korea

The interscalene brachial plexus block is not commonly used in pediatric regional anesthesia. The increasing popularity of ultrasound has allowed more anesthesiologists to perform regional anesthesia with high success rates in pediatric patients with the direct visualization of the target nerve and spread of local anesthetics. We present a case of interscalene brachial plexus block under ultrasound guidance in a 17-month-old child with acute drug-induced hepatitis who required fixation of a fracture of the lateral humeral condyle. (Korean J Anesthesiol 2012; 62: 568-570)

Key Words: Brachial plexus, Pediatrics, Regional anesthesia, Ultrasonography.

Regional anesthesia in pediatric patients is always challenging [1]. The recent introduction of ultrasound in pediatric regional anesthesia has made it more popular by enabling the direct visualization of target nerves and surrounding structures [2]. Although several ultrasound-guided regional techniques in children have been introduced, only a few articles had been published about ultrasound-guided interscalene brachial plexus block (US-ISB) in pediatric patients [3,4].

The efficacy of US-ISB for anesthesia and analgesia after orthopedic surgery has been established in adults, but not in children. We present a case of US-ISB in a child with acute druginduced hepatitis undergoing surgery for correction of a lateral humeral condyle fracture.

\section{Case Report}

A 17-month-old boy weighing $14 \mathrm{~kg}$ was diagnosed with a fracture of the right lateral humeral condyle and scheduled for open reduction and internal fixation with a kwire. He had suffered from an upper respiratory infection for the previous 3 weeks and drug-induced hepatitis developed as a result of his medication. The preoperative serum alanine aminotransferase (ALT) and serum aspartate aminotransferase (AST) levels were 177 and $76 \mathrm{IU} / \mathrm{L}$, respectively. Other laboratory exams were normal, except for mild anemia ( $\mathrm{Hb} 8.8 \mathrm{~g} / \mathrm{dl}$ ). A pediatrician recommended delaying the surgery for about 4 weeks, but early intervention is needed for fractures of the lateral condyle of the

Received: April 6, 2011. Revised: 1st, May 3, 2011; 2nd, June 12, 2011; 3rd, June 20, 2011. Accepted: June $20,2011$.

Corresponding author: Joon-Ho Lee, M.D., Ph.D., Department of Anesthesiology and Pain Medicine, Soonchunhyang University, Bucheon Hospital, 1174, Jung-dong, Wonmi-gu, Bucheon 420-767, Korea. Tel: 82-32-621-5340, Fax: 82-32-621-5322, E-mail: anpjuno@gmail.com (c)This is an open-access article distributed under the terms of the Creative Commons Attribution Non-Commercial License (http:// creativecommons.org/licenses/by-nc/3.0/), which permits unrestricted non-commercial use, distribution, and reproduction in any medium, provided the original work is properly cited. 
humerus in pediatric patients.

We decided to proceed with the surgery under an interscalene brachial plexus block without supplementary general anesthesia. Written informed consent was obtained from the patient's parent. After intravenous access was secured in the left forearm, $20 \mu \mathrm{g}$ of fentanyl and $50 \mathrm{mg}$ of thiopental sodium were administered. Under mask-assisted ventilation, the patient was placed in the supine position with the neck rotated slightly to the left. The skin was prepared in typical sterile fashion. The brachial plexus was identified using the MTurbo ultrasound system (SonoSite, Bothell, WA, USA) with a 13-6 MHz 25-mm high-frequency linear array transducer (SLAx; SonoSite).

A transverse scan was performed at the level of the interscalene groove with the long axis of the probe parallel to the clavicle. Then, the transducer was moved slightly in the caudal direction until the brachial plexus roots were identified between the anterior and middle scalene muscles. After the transducer position was confirmed, $1 \%$ mepivacaine was applied in a skin wheal and a 25-mm, 24-guage insulated needle (Stim-A2250, B. Braun Medical, Bethlehem, PA) was advanced using the inplane technique. Once the needle reached the brachial plexus, the nerve stimulator (Maxistim; Life-Tech, Stafford, TX) was turned on, starting from $1.5 \mathrm{~mA}$ and decreasing to $0.5 \mathrm{~mA}$ to elicit contraction of the deltoid and biceps muscles. After confirming needle placement, $1.5 \mathrm{ml}$ of $0.5 \%$ ropivacaine was injected carefully with intermittent negative aspiration (Fig. 1). Successful blockade was determined by the absence of a withdrawal response and hemodynamic changes in response

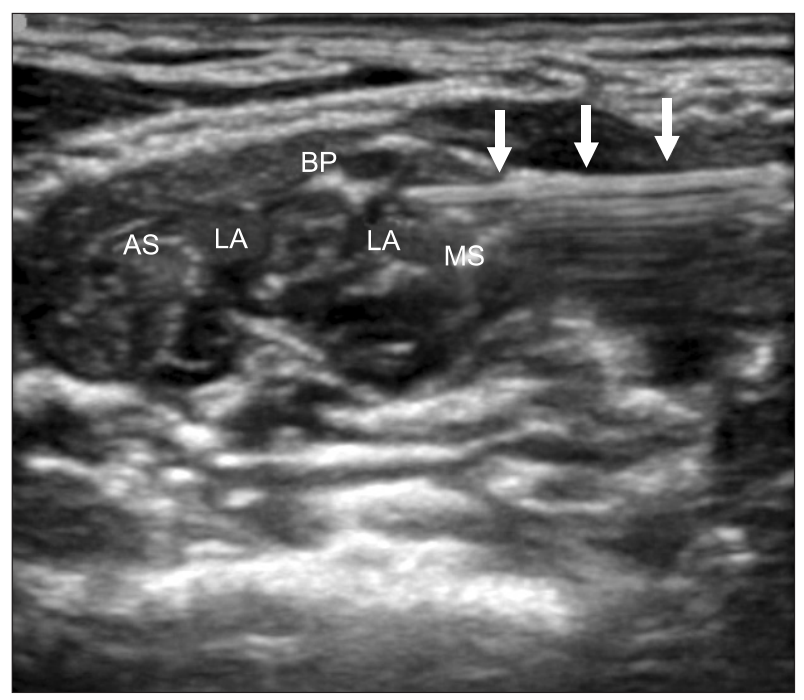

Fig. 1. Ultrasonographic image of the interscalene region during brachial plexus blockade. The brachial plexus is surrounded by local anesthetics after injecting $1.5 \mathrm{ml}$ of $0.5 \%$ ropivacaine. The arrow indicates the needle. AS: anterior scalene muscle, MS: middle scalene muscle, BP: brachial plexus, LA: local anesthetic. to surgical stimuli, such as the skin incision.

After block placement, surgery was performed uneventfully; the duration of surgery was about $20 \mathrm{~min}$. No additional sedative or analgesic was administered and the patient's vital signs were stable during surgery. Postoperatively, a chest X-ray showed no elevation of the right diaphragm and the ALT and AST were 108 and $62 \mathrm{IU} / \mathrm{L}$, respectively. He had excellent postoperative pain relief for 2 days after surgery and was discharged on the third day with no evidence of neurologic sequelae. Three days after discharge, he visited the orthopedic clinic for follow-up assessment and was still free of any neurological deficit.

\section{Discussion}

Although the potential for nerve injury exists, regional anesthesia in pediatric patients is usually performed under deep sedation or general anesthesia. The use of ultrasound in peripheral nerve blockade can reduce the risk of such complications by providing more accurate localization of the target nerve and other 'dangerous' structures, such as blood vessels, the peritoneum, and pleura. Presently, the use of ultrasound has become common when performing peripheral nerve blockade in pediatric regional anesthesia. Moreover, ultrasound has allowed more anesthesiologists to perform nerve blocks with high success rates in pediatric patients. The greatest potential limitation to this technique is likely the availability of equipment and the need for well-trained operators [2].

Regional anesthesia in children has several benefits in addition to the simple avoidance of general anesthesia, including decreased perioperative opioid use and stress responses. Moreover, the better analgesia offered by regional anesthesia also shortens recovery time and improves the outcome [5-7].

In our patient, general anesthesia was to be avoided due to the elevated liver enzymes. Moreover, he still had a symptomatic upper respiratory infection, with rhinorrhea, a sore throat, and intermittent cough at the time of surgery, constituting another problem for performing general anesthesia.

Surgery for the fixation of lateral humeral condyle fractures can be performed readily under a supraclavicular brachial plexus block. Nevertheless, we choose the US-ISB for the following reasons. First, our patient suffered from acute drug-induced hepatitis. Although single-dose blocks can be performed safely with normal doses of local anesthetics, even in patients with severe hepatic dysfunction [8], a relatively larger dose of local anesthetic is needed for a supraclavicular brachial plexus block compared with an interscalene block, even under ultrasound guidance [9]. Berde suggested safe dosing guidelines for the use of bupivacaine in pediatric patients [10], but no data are available on the safety of peripheral nerve block with a large amount of a modern, less toxic local anesthetic in children, such 
as ropivacaine or levobupivacaine [2]. Second, a supraclavicular brachial plexus block has the potential risk of pneumothorax, which can be reduced by using an ultrasound-guided technique [11]. However, the risk of pneumothorax is greater in infants and small children because the apex of the lung is situated in a more rostral position [12] and complete avoidance of this complication is difficult, even using an ultrasound-guided technique [13].

The major concern when performing an interscalene brachial plexus block is hemidiaphragmatic paralysis. In adults, the incidence of this complication is $100 \%$ and it does not usually cause respiratory insufficiency [14]. This can be reduced by using an ultrasound-guided technique [15]. However, there is no report on the incidence and risk of this complication in children. Although no objective assessment of hemidiaphragmatic paralysis, such as an ultrasound exam or spirometry, was performed, the postoperative chest X-ray did not show hemidiaphragmatic elevation in our patient.

In conclusion, we successfully and safely performed an ultrasound-guided interscalene brachial plexus block in a small child in whom general anesthesia was not feasible, without complications. It also provided satisfactory postoperative analgesia. Further prospective trials are needed to confirm the efficacy and safety of this practice.

\section{References}

1. Tsui B, Suresh S. Ultrasound imaging for regional anesthesia in infants, children, and adolescents: a review of current literature and its application in the practice of extremity and trunk blocks. Anesthesiology 2010; 112: 473-92.

2. Willschke H, Marhofer P, Machata AM, Lonnqvist PA. Current trends in paediatric regional anaesthesia. Anaesthesia 2010; 65 Suppl 1: $97-$ 104.

3. Jan van Geffen G, Tielens L, Gielen M. Ultrasound-guided interscalene brachial plexus block in a child with femur fibula ulna syndrome. Paediatr Anaesth 2006; 16: 330-2.
4. Mariano ER, Ilfeld BM, Cheng GS, Nicodemus HF, Suresh S. Feasibility of ultrasound-guided peripheral nerve block catheters for pain control on pediatric medical missions in developing countries. Paediatr Anaesth 2008; 18: 598-601.

5. Anand KJ, Carr DB. The neuroanatomy, neurophysiology, and neurochemistry of pain, stress, and analgesia in newborns and children. Pediatr Clin North Am 1989; 36: 795-822.

6. Kehlet H. Epidural analgesia and the endocrine-metabolic response to surgery. Update and perspectives. Acta Anaesthesiol Scand 1984; 28: 125-7.

7. McNeely JK, Farber NE, Rusy LM, Hoffman GM. Epidural analgesia improves outcome following pediatric fundoplication. A retrospective analysis. Reg Anesth 1997; 22: 16-23.

8. Rosenberg PH, Veering BT, Urmey WF. Maximum recommended doses of local anesthetics: a multifactorial concept. Reg Anesth Pain Med 2004; 29: 564-75.

9. Moayeri N, Bigeleisen PE, Groen GJ. Quantitative architecture of the brachial plexus and surrounding compartments, and their possible significance for plexus blocks. Anesthesiology 2008; 108: 299-304.

10. Berde CB. Toxicity of local anesthetics in infants and children. J Pediatr 1993; 122: S14-20.

11. De Jose Maria B, Banus E, Navarro Egea M, Serrano S, Perello M, Mabrok M. Ultrasound-guided supraclavicular vs infraclavicular brachial plexus blocks in children. Paediatr Anaesth 2008; 18: 83844.

12. Polaner DM, Suresh S, Coté CJ. Regional Anesthesia. In: A Practice of Anesthesia for Infants and Children. 4th ed. Edited by Coté Charles J. LJ, Todres I. David: Philadelphia, W.B. Saunders. 2009, p 895.

13. Bhatia A, Lai J, Chan VW, Brull R. Case report: pneumothorax as a complication of the ultrasound-guided supraclavicular approach for brachial plexus block. Anesth Analg 2010; 111: 817-9.

14. Urmey WF, Talts KH, Sharrock NE. One hundred percent incidence of hemidiaphragmatic paresis associated with interscalene brachial plexus anesthesia as diagnosed by ultrasonography. Anesth Analg 1991; 72: 498-503.

15. Renes SH, Rettig HC, Gielen MJ, Wilder-Smith OH, van Geffen GJ. Ultrasound-guided low-dose interscalene brachial plexus block reduces the incidence of hemidiaphragmatic paresis. Reg Anesth Pain Med 2009; 34: 498-502. 